\title{
Hardware in Loop Simulation to Control the Speed of DC Motor by using PID Controller
}

\author{
Ravindra Gaur \\ Electrical Engineering Department \\ Delhi Technological University \\ Delhi
}

\begin{abstract}
Speed Control of a DC Motor is essential thing in Robotics and other industrial application. There are various methods available to control the rotational speed of DC motor. In this paper the real time rotational speed control of a DC motor is presented. To control the rotational speed of DC motor in real time, controller is designed with the help of Matlab tool and the complete Hardware is interfaced with the laptop through USB port with the help of Arduino Mega Board. The low cost hardware consists of one drive motor as generator, another motor used as a sensor coupled with the drive motor, one L293D IC and an arduino mega board for interfacing with laptop. This kind of work is useful for the university students to understand the working, implementation and testing of various controller in real time. Hardware can be used to test any kind of controller designed in the Matlab.
\end{abstract}

\section{Keywords}

Real time hardware in Loop control, PID Control, Arduino mega 2560, Serial communication, Pulse Width Modulation

\section{INTRODUCTION}

DC motor is an integral part of the robotics and other industrial application. The rotational speed of the dc motor can be controlled by using terminal voltage controlled method. The rotational speed of the dc motor is related to the supplied input voltage, by applying constant input voltage, speed of the motor is changed by switching the supply voltage on and off so regularly that the motor notice only the average voltage effect[1] and not the switching operation. The speed of the DC motor is varies by using PWM technique.

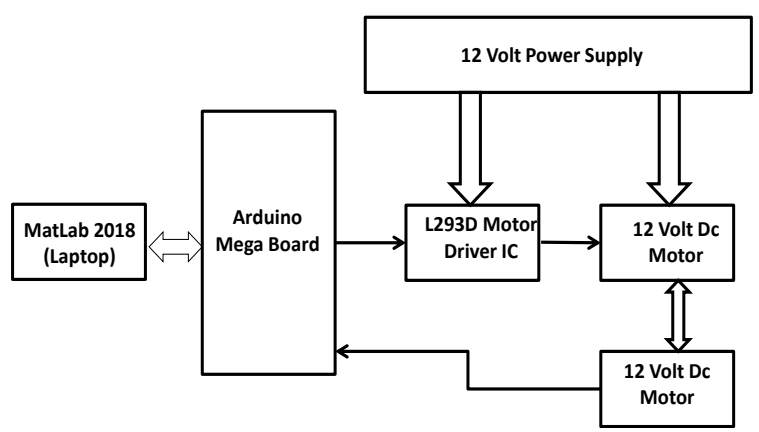

Figure 1: Block Diagram of the hardware system

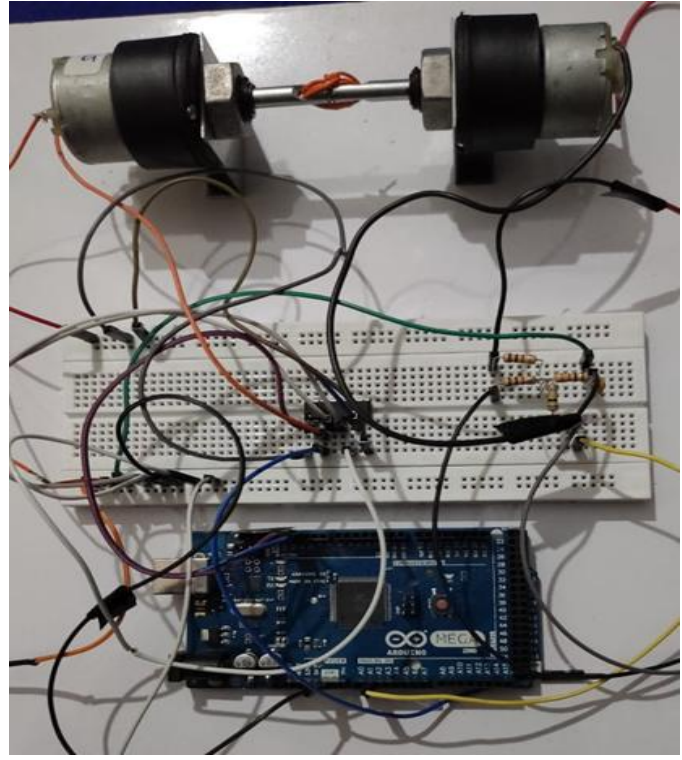

Figure 2: Actual Hardware

\section{SYSTEM DESCRIPTION}

An easiest technique to control the rotational speed of the DC motor is to control its terminal voltage. The higher the voltage, the speed of motor is Maximum. To control the voltage, PWM technique is used. In PWM method, the operating power of the motors is turned on and off to modulate the current of the motor. The ratio of "on" time to "off" time determines the speed of the motor.

The Speed of the DC motor is relative to the terminal voltage. If the voltage is low the speed of motor is less and if the voltage is more than the speed of motor is up to maximum rotational speed specified in datasheet of motor. The terminal voltage is controlled by using the PWM techniques. The major components of the System are.

\subsection{Arduino Mega Board}

Please Arduino Mega is a general purpose open architecture microcontroller board based on ATmega2560 which consist of 54 no. of digital Input Output pins out of which 14 pins can be used as PWM output and 16 pins can be used as analog inputs. It also contains 4 UART (Hardware Serial Ports), a 16 Mhz crystal Oscillator, a D-type USB connector and power jack etc. 


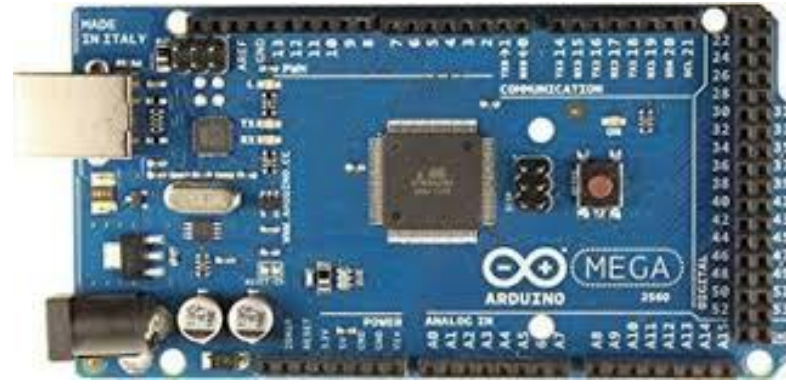

Figure 3: Arduino Mega 2560 Board

In this project the arduino board is used to provide interfacing between the hardware and Matlab running on laptop.

\subsection{Driver IC (L293D)}

L293D is a 16 pin motor driver IC, which can be used to drive two different motor independently. The direction and rotational speed of motor can be controlled by using this IC. There are two power Pins in this IC, one (5 volt) for the IC to work, this must be connected to +5 volt supply. Another power pin is used to drive the motor, based on specification of motor.

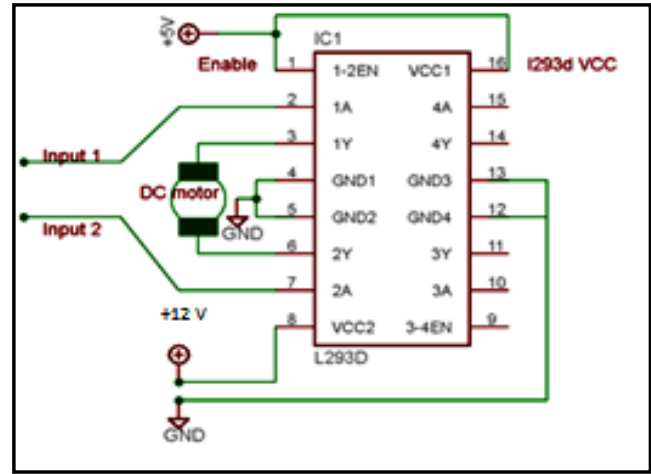

Figure 4: Internal Diagram of IC L293D

In this project only one drive motor is used so only one set of drive IC pins are getting used.

\subsection{Motor}

DC Motor is a kind of electric machine, which transforms electrical energy into mechanical energy. In this project two 12 Volts 500 RPM dc motor is used one as a motor and another one as generator. The Rotation per minute (RPM) speed of the motor is controlled by using variable terminal supply voltage. A 12 volts DC motor is inexpensive, small and powerful enough to be used in many application such as tolls, toys and automobile mechanisms.

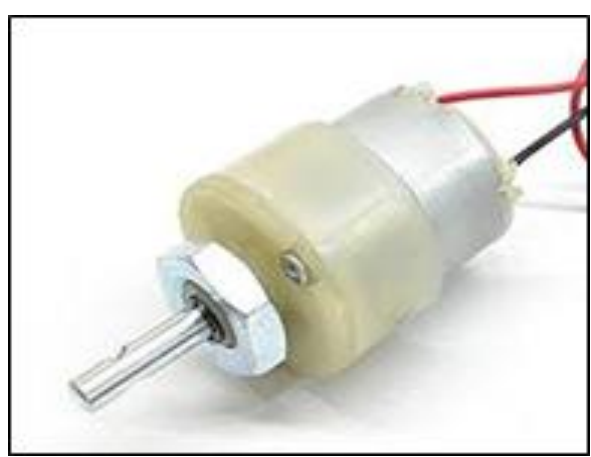

Figure 5: 12 Volt, 500 RPM DC motor

\section{PLANT MODELING}

The interface of the hardware is done with the MATLAB Simulink toolbox as per block diagram shown in figure.

\subsection{Open Loop block diagram and response}

The open loop Simulink model of plant is shown in figure 5 . The output response of the system is shown in figure 7.

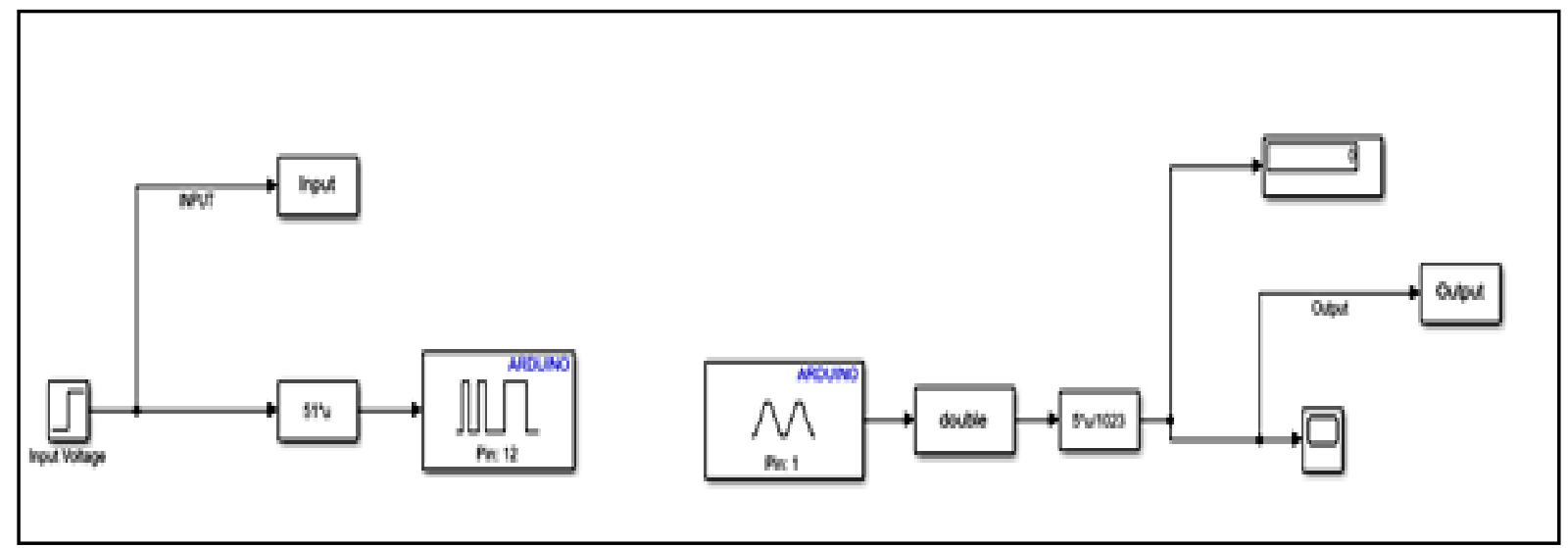

Figure 6: Open loop Simulation Diagram of the System 


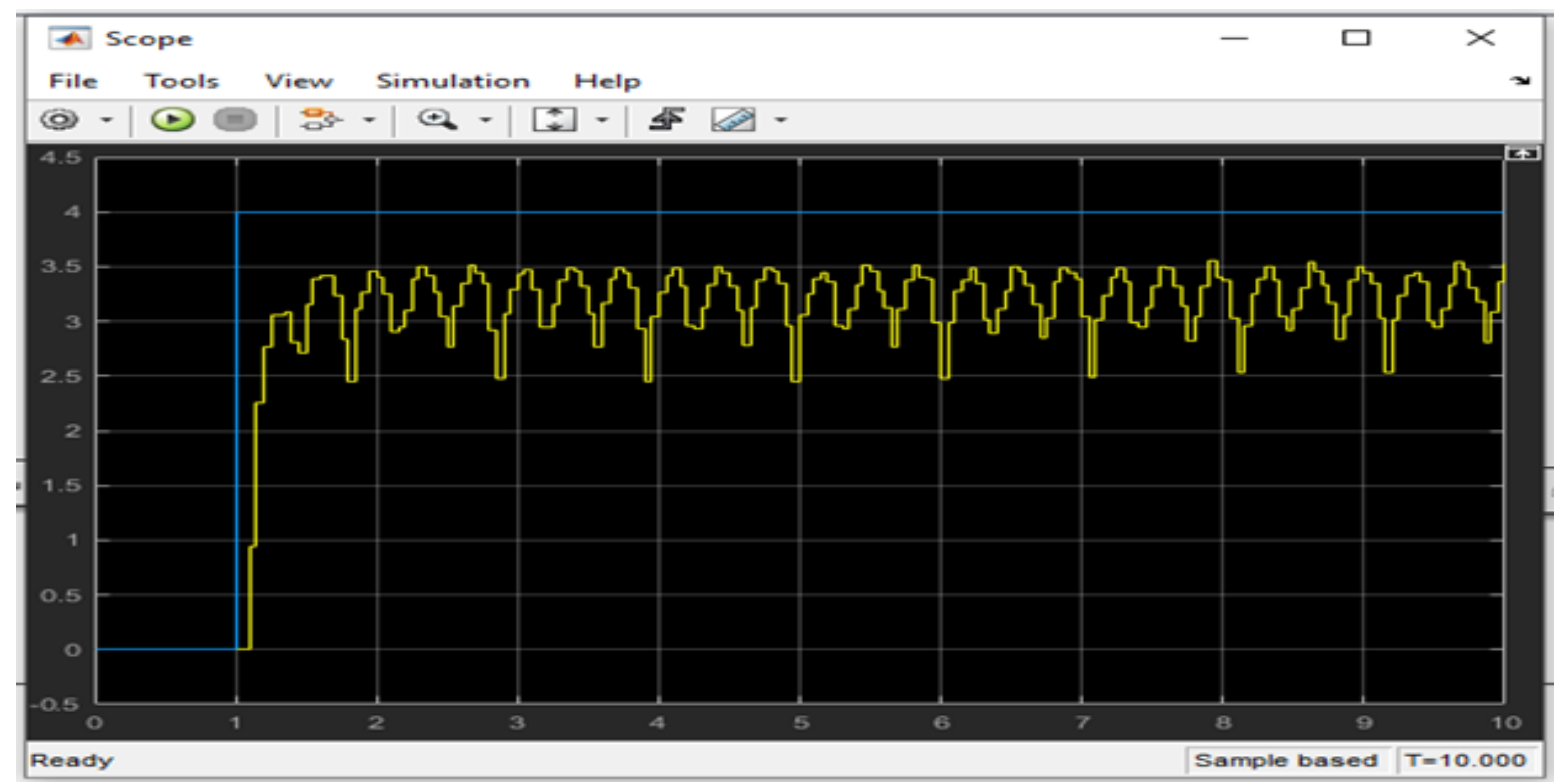

Figure 7: Open loop Output Response

\subsection{Transfer Function}

Transfer function of the hardware is estimated by using System Identification toolbox of Matlab.

Transfer Function

45610

$s^{\wedge} 4+32.28 s^{\wedge} 3+525.1 s^{\wedge} 2+11340 s+54730$

\subsection{PID Controller Design}

PID controller is still the most widely used controller in industries because of its simplicity and cost-effectiveness. The output of the controller depends on proportional Gain constant (Kp), Integral Gain constant (Ki) and Derivative Gain Constant (Kd). The mathematical equation of the PID controller is given below.

$$
\mathrm{u}(\mathrm{t})=\mathrm{Kp} * \mathrm{e}(\mathrm{t})+\mathrm{Ki} * \int \mathrm{e}(\mathrm{t}) \mathrm{dt}+\mathrm{Kd} * \frac{d}{d t} \mathrm{e}(\mathrm{t}) \ldots \ldots(1)
$$

$$
\mathrm{U}(\mathrm{s})=\left(\mathrm{Kp}+\mathrm{Ki} * \frac{1}{s}+\mathrm{Kd} * \mathrm{~s}\right) * \mathrm{E}(\mathrm{s})
$$

The tuning parameter of the PID Controller ( $\mathrm{Kp}, \mathrm{Ki}, \mathrm{Kd}$ ), is optimized by using the auto-tuning feature of PID Controller on Matlab.

\section{Controller Transfer Function}

$0.01 \mathrm{~s}^{\wedge} 2+0.01 \mathrm{~s}+1$

$=\mathrm{s}$

\section{CLOSE LOOP SIMULINK MODAL WITH OUTPUT RESPONSE}

The close loop Simulink block diagram is shown in figure 8 . PID controller is used control the rotational speed of DC motor. The output response of the system is shown in figure 9 . Where blue line represents the step input and yellow line represents the output of the system. The oscillation around the steady state is because of the noise present in the system.

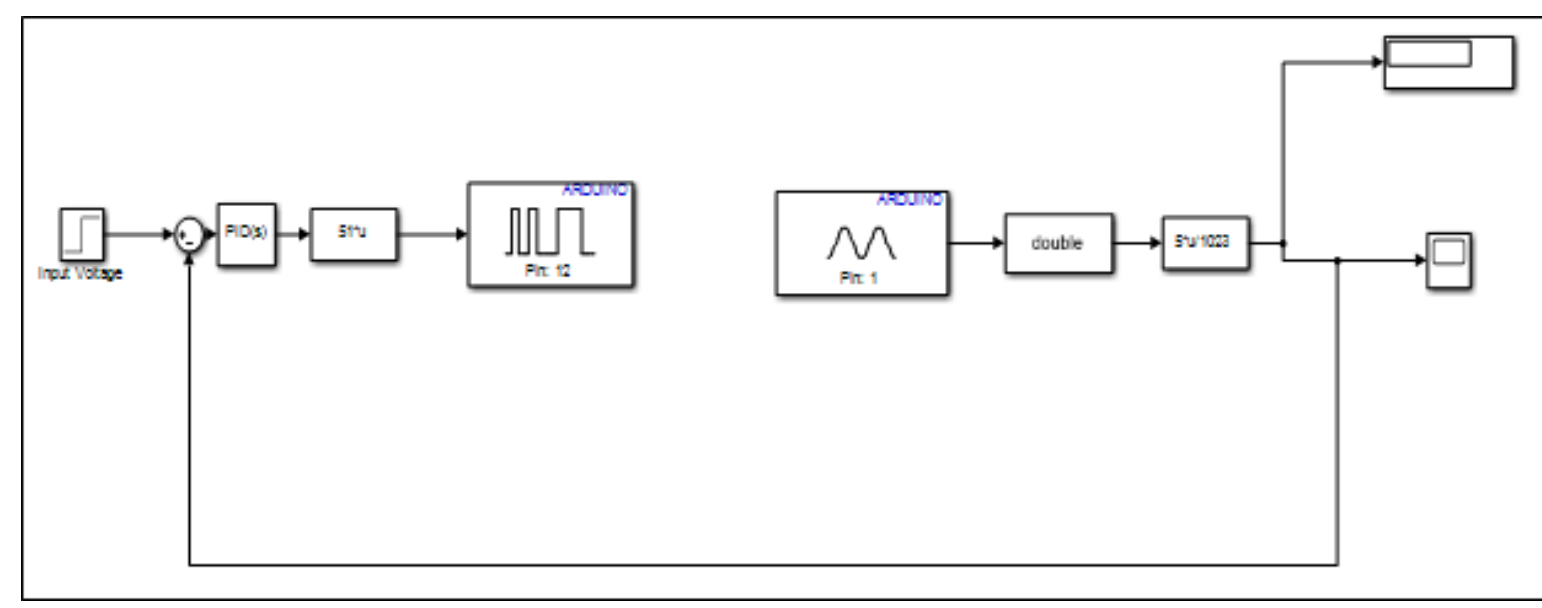

Figure 8: Close Loop simulation diagram of the System 


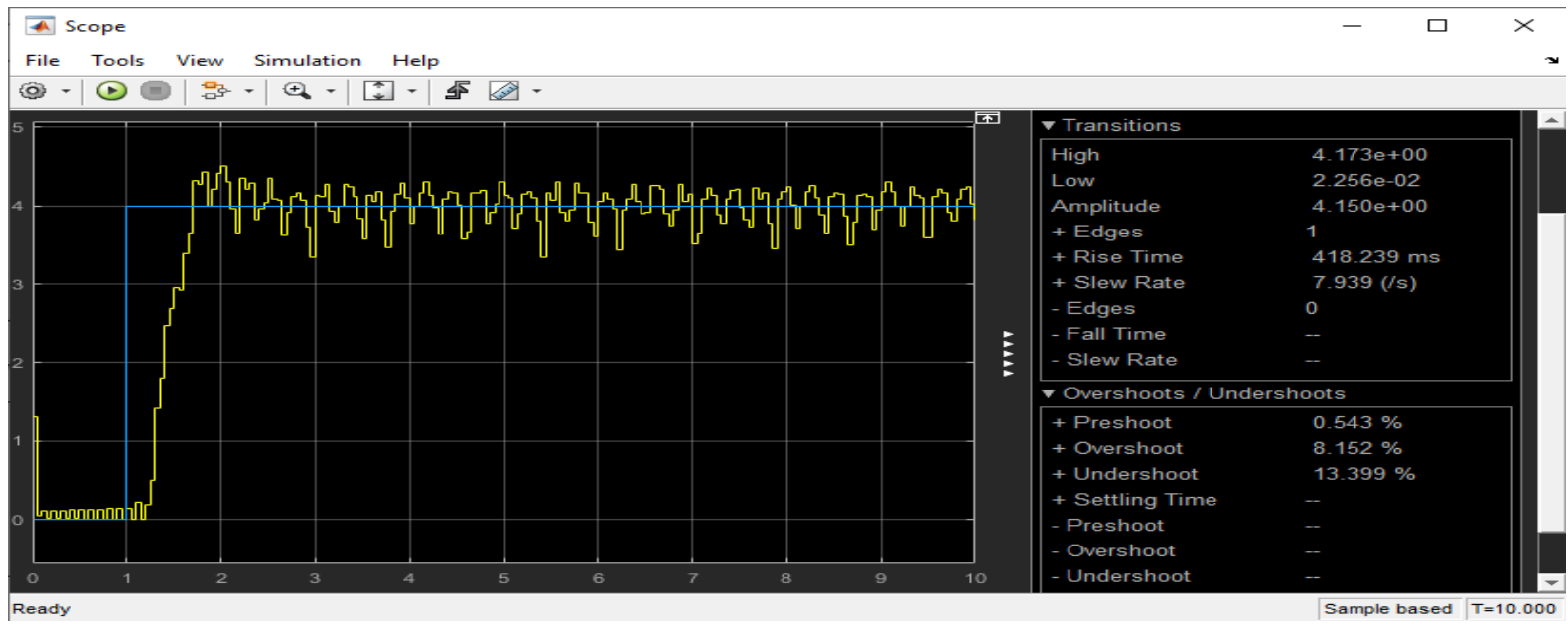

Figure 9: Close loop Response of the system

\section{RESULTS}

The objective of this project was to develop a low cost hardware, which may be used to test different controllers designed in Matlab Simulink. The PID controller is designed in Matlab and tested with this hardware. The performance of the PID controller is satisfactory as shown in figure 9. Furthermore same hardware can be used test other controllers designed in Matlab. Instead of PID controller block in figure 8 other optimized controller block can be used to test the performance of controller with the hardware.

\section{CONCLUSION}

In this paper, the real time hardware in loop control of a DC motor setup by using PID controller with Arduino Mega Board is presented. The main objective of this project is to create a low cost platform for better understanding, implementation and real time testing of different controllers developed in industries and laboratories for training purpose.

\section{ACKNOWLEDGMENTS}

This work was done in the Electrical Engineering Department of Delhi Technological University, Delhi. The author thanks Dr. Sudarshan K. Valluru, Mrs. Seema Sharma, Dr. Zaheer Ahmad Ansari and Mr. Avnish Kumar for sharing their valuable Knowledge without which this work could not have been accomplished.

\section{REFERENCES}

[1] Gavran, M., Fruk, M., \& Vujisić, G. (2017, May). PI controller for DC motor speed realized with Arduino and Simulink. In 2017 40th International Convention on Information and Communication Technology, Electronics and Microelectronics (MIPRO) (pp. 15571561). IEEE.

[2] Thirupathi Allam, Matla Raju, S. Sundeep Kumar, "Design of PID controller for DC Motor Speed Control Using Arduino Microcontroller", (IRJET 2016) Volume: 03, Issue: 09 .

[3] Hardik S Jain, Akshat Palak, Sandesh Agrawal, Krishnam Tibrewal, Malaya kumar Hota, "DC motor Speed Control using PID Controller, IR Sensor and PWM Hysteresis" (IJITEE), ISSN: 2278-3075, Volume8, Issue-6, April 2019.
[4] Shuvra Prokash Biswas, Md. Kamal Hosain, Md. Waliur Rahman (2017, IEEE) “ Real - Time Arduino Based Simulator Enabled Hardware-in-the-loop Electric DC Machine Drive System.

[5] Barber, Ramón, Mario De La Horra Köllmer, and Jonathan Crespo. "Control Practices Using Simulink with Arduino As Low Cost Hardware." In ACE, pp. 250-255. 2013.

[6] Nawi Berahim, Sulaini Besar, Mohd Zani, Abdul Rahim, Shamsul Aizam Zulkifli, Zairi Ismael Rizman, "PID Voltage control for DC Motor Using MATLAB Simulink and Arduino Microcontroller", ISSN: 20904274, J. Appl. Environ. Biol. Sci., 5(9) 166-173, 2015.

[7] Hirdesh Kr.Saini, Shahid Firoz, Ashutosh Pandey (2017, April) "Arduino Based DC Motor Speed Control". IJRDO - Journal of Electrical And Electronics Engineering, Volume - 3, ISSN: 2456-6055.

[8] Asha, K. R., Tasleem, P. S., Kumar, A. R., Swamy, S. M., \& Rekha, K. R. (2017, March). Real Time Speed Control of a DC Motor by Temperature Variation Using LabVIEW and Arduino. In 2017 International Conference on Recent Advances in Electronics and Communication Technology (ICRAECT) (pp. 72-75). IEEE.

[9] Hat, M., Ibrahim, K. K., Salam, B., Mohd, T. A. T., \& Hassan, M. K. (2015). Model Based Design of pid controller for BLDC motor with implementation of embedded arduino mega controller.

[10] Vikhe, P., Punjabi, N., \& Kadu, C. (2014). Real time DC motor speed control using PID controller in LabVIEW. International Journal of Advanced Research in Electrical, Electronics and Instrumentation Engineering, 3(9), 12162-12167.

[11] Shetti, P. R., \& Mangave, A. G. (2014). DC Motor Speed Control with Feedback Monitor Based on C\# Application. International Journal of Research in Engineering and Technology, 3(3), 398-401. 